\title{
Cultural Diversity and its Influence on the Attitudes of Africans and Indians toward Marketing Communication: A South African Perspective
}

\author{
Abosede Ijabadeniyi, Jeevarathnam Parthasarathy Govender, Dayaneethie Veerasamy \\ Durban University of Technology, Durban, South Africa \\ bosede55@yahoo.com,govendej@dut.ac.za,veerasamyd@dut.ac.za
}

\begin{abstract}
Culture has been reported to be one of the major factors influencing attitudes toward marketing communication. However, identification across prevailing cultural dimensions could have unique implications for attitudes toward marketing communication. This paper examines how African and Indian cultural values may or may not influence attitudes toward marketing communication. It explores how Africans converge with or diverge from Indians with regards to culturally sensitive attitudes toward marketing communication, based on a Marketing Communication-Specific Cultural Values (MCSCV) model adapted from the individualismcollectivism constructs. Attitudes toward marketing were measured based on the advertising scale of the Index of Consumer Sentiment toward Marketing (ICSM) practices. Data generated for this study were based on responses provided by 283 and 92 African and Indian shoppers at the main shopping malls in the most predominant African and Indian townships in Durban, South Africa viz. Umlazi and Chatsworth, respectively. Analysis of Variance (ANOVA) and Categorical Principal Component Analysis (CATPCA) were conducted on the dataset. Findings revealed that both races displayed more individualistic than collectivistic tendencies toward marketing communication, but Africans exhibited more collectivistic tendencies than their Indian counterparts. In addition, respondents' individualistic tendencies have a significant influence on attitudes toward marketing communication which showed that consumers' indigenous cultural disposition play a moderating role on attitudes toward marketing communication. This study builds on the marketing literature by validating the implications of cultural diversity for marketing communication. The study emphasizes how the interplay between target markets' underlying cultural dispositions and cultural values held toward marketing communication, influence the consistency or inconsistency in consumers' attitudes toward marketing communication.
\end{abstract}

Keywords: Culture, Individualism, Collectivism, Consumer behaviour, Advertising

\section{Introduction}

Cultural diversity is a prominent issue in a country like South Africa, which has a history of social segregation (Ndhlovu, 2011) and a diversified racial classification consisting of Africans (80.5\%), Coloured (8.8\%), Indian $(2.5 \%)$ and White $(8.3 \%)$ (StatsSA, 2015). Such diversity lends itself to prejudiced interpretations of cues (Ghemawat and Reiche, 2011). The understanding of cultural differences is particularly crucial for successful advertising campaigns, given the proliferation of global trends (Uskul and Oyserman, 2010). While such understanding is not only important for enhancing the global competitiveness and adaptability of advertising campaigns, it is critical for generating sources of strategic competitive advantage. For example, MacDonald uses culturally sensitive campaigns and menus across the countries in which it operates (Jandt, 2013). Unilever is also known for adapting local contents and cultural cues to its products, packaging and marketing communication strategies (Quester, Pettigrew and Hawkins, 2011). However, the ability to understand culturally sensitive behaviour and adapt advertising campaigns to local contents is moderated by consumers' attitudes (Baek and Morimoto, 2012). de Mooij (2011) maintained that the predictability of attitude-based consumer behaviour has been linked to consumers' identification with the individualism and collectivism cultural dispositions. The author further argued that individualistic and collectivistic cultural dispositions are a reflection of the importance consumers place on the 'self' and 'community members', respectively. Morling and Lamoreaux (2008) also reported on the diversity in the attitudes of individualists and collectivists toward stimuli.

The dissemination of culturally sensitive marketing messages is one of the major challenges marketing practitioners encounter in a culturally diverse market such as South Africa (Ghemawat and Reiche, 2011). Regardless of the ubiquity of the spirit of Ubuntu; the implicit force that govern the values of South African camaraderie (Theron and Theron, 2010); diversity still exists amongst minority groups based on religion, language, and lifestyle (Du Plessis and Rousseau, 2007). South Africa has a unique cultural structure, 
consisting of various cultures and subcultures. The influence of the historical and socio-cultural framework of the South African society (Bhaktawar and Burger, 2010) on consumers' attitudes toward stimuli cannot be overemphasized (Soontiens and De Jager, 2008). While the latter is responsible for the proliferation of cultural diversity, there is a growing need for more research on how the cultural disposition of consumers influences the predictability of attitudes toward stimuli. Therefore, consumers' cultural diversity has implications for marketing practitioners, given the diversity in the interpretations consumers give to stimuli (Usunier and Lee, 2013). Research into cultural influences on consumer behaviour is especially needed in a multicultural society such as South Africa, given the scarcity of such research in Africa (Oyedele and Minor, 2012). The culturally diverse nature of the South African market therefore makes an investigation into how Africans ${ }^{1}$ and Indians ${ }^{2}$ of the South African origin, perceive marketing communication timeous. This study draws from Hofstede's individualism and collectivism dimension to develop a scale measuring consumer's marketing communication-specific cultural values (MCSCV). The objective of this paper is to investigate how consumers' individualistic or collectivistic disposition to marketing communication influences attitudes toward marketing communication. The paper will also explore how consumers' indigenous cultural dispositions moderate attitudes toward marketing communication.

Theoretical Background: Geert Hofstede's five cultural dimensions viz. Individualism-Collectivism, Masculinity-Femininity, Power Distance, Uncertainty Avoidance and Long-Short Term Orientation, which were borne out of his two pioneering cross-national studies including 100,000 IBM workers across 50 and 23 countries, respectively (de Mooij, 2011), have been largely adapted to test cultural influences on stimuli across diverse fields (Shulruf, Hattie and Dixon, 2011). Hofstede's cross-national study revealed that South Africa ranked high on the individualism index. However, the findings generated for South Africa were based on responses from white South Africans only. The findings further showed that India ranked low on the individualism index, which implies that India tends toward collectivism (Hofstede, Hofstede and Minkov, 2010). The individualism scores generated for South Africa negate the values fostered by the spirit of Ubuntu, which was coined from the following phrase: "umuntu ngu muntu nga bantu" meaning: "A person is a person through other people" (Oyedele and Minor, 2012).

The South African cultural values significantly show high collectivistic rather than individualistic tendencies. The underlying cultural framework of South Africans in general is centered on the tenets of Ubuntu. The values of Ubuntu are centered on striving toward living in harmony with community members. South African people generally view themselves as belonging together and inseparable from the community. A person is perceived by community members as ideal, if they possess Ubuntu virtues (Broodryk, 2008). However, the scores obtained for India confirm the prevailing cultural disposition identified in India viz. collectivism (Vaheed, Deshai and Waetjen, 2010). Therefore, the influence of the spirit of Ubuntu on Africans as well as the underlying cultural dispositions of South African Indians, based on their Indian origin, were problematised from a marketing communication point of view. Uskul and Oyserman (2010) argued that values are situationspecific. They further contend that consumers will switch values on different occasions in response to situational factors such as societal expectations, peer and reference groups, globalised and acculturated values. These findings tie with Fishbein's behavioral intentions model, otherwise known as the theory of reasoned action. Fishbein maintained that consumer behaviour is influenced by some attitudinal and social components which make consumers conform to situational factors which are determined by expectations from others (de Mooij, 2011). Adapting this theory to the present study leads to the proposition that situational factors will influence consumers' value switching behaviour.

The proliferation of these situational factors, given increasing global trends, makes consumers' value switching behaviour critical for marketing practitioners. This study aims to validate consumers' value switching behaviour from the point of view of Africans and Indians. While Hofstede's cross-national study reveals that Africans and Indians scored low on the individualism index (Hofstede et al., 2010), this study investigates the extent to which consumers' MCSCV influence attitudes toward marketing communication. The study also explores the relationship between consumers' underlying cultural values and attitudes toward marketing communication and, the implications of this for marketing practitioners. The following are the proposed hypotheses:

H1: Respondents' collectivistic tendencies will have significant influence on attitudes toward marketing communication 
H2: Africans and Indians differ significantly based on the relationship between their demographic profile and attitudes toward marketing communication

${ }^{1}$ Africans are also referred to as black South Africans. ${ }^{2}$ Indians are South Africans of Indian origin.

\section{Literature Review}

Attitudes are consumers' positive or negative evaluations of and response to stimuli, which are to a large extent based on learning and the interpretations given to learning (Blythe, 2008). Quester et al. (2011) also conceded to Blythe's proposition by affirming those consumers' attitudes toward stimuli range between positive and negative outcomes. Attitudes toward stimuli are not categorized as behaviour, but as moderators of behaviour. Attitudes toward marketing communication can vary based on the extent to which consumers perceive marketing communication as informative, annoying, dispensable, enjoyable and deceptive (Bearden et al., 2011). deMooij (2011) appraised attitudes from a cultural perspective by affirming that consumers in individualistic cultures show relatively consistent attitudes toward stimuli while attitudes toward stimuli in collectivistic cultures are inconsistent. Culture is the structure and the unconscious assumptions that give meaning to how the world operates (Samovar et al., 2010). The authors further reiterated that the former explain the "how" and "why" of a culture's collective action". Culture's role is evident in the interplay between the institutional and environmental factors influencing consumer behaviour. While cultural influences are visible in artifacts, values, practices, norms, rituals, and heroes, some cultural influences are not noticeable as intrinsic culturally sensitive consumer behaviour are often difficult to identify (Sen, Du, and Bhattacharya, 2016). Scholars such as Ghemawat and Reiche (2011) and Chan (2010) argued that globalisation and its agents are the major forces responsible for consumers' convergent cultural attributes. The authors further contend that due regard should therefore be accorded to the hybridisation of cultural values and its implications for marketing communication, as a result of acculturation. Instances of the proliferation of acculturated values are also prevalent in literature as acculturation is viewed by consumers as the 'ticket' into the global culture (Hofstede et al., 2010).

In addition, culture has been reported to be one of the antecedents to advertising avoidance (Prendergast et al., 2010). Brittany and Ronald (2011) also conceded to this notion by affirming that culture influences consumers' avoidance of social media advertising; advertisements on a webpage which also results in negative attitudes toward the advertised brand. Similarly, Baek and Morimoto (2012) contributed to this body of knowledge by confirming that advertising scepticism can result from cultural influences.A study conducted in New Zealand reveals the impact of beliefs, preferences for family members and marketing communication on consumers' attitudes towards local and national brands, to confirm that brands are symbolic in the formation of an identification with national identities. Consumers therefore use brands to facilitate cultural meanings and national identities (Bulmer and Buchanan-Oliver, 2010). The use of numbers and colors in marketing communication has also been identified as critical across cultures (Jandt, 2013). Solomon's (2013) commentary also confirmed the culturally diverse use of marketing communication cues across cultures. The author gives an analogy of cultures which prohibit the use of women, nudity, displays of underwear on mannequins, inappropriate non-verbal communications and modes of dressing in advertisements. For example, the attachment of luck to the number 'seven' in Western countries, and to the number 'eight' in Asian countries such as China, influenced the timing of the last Olympics held in Beijing on 8/8/2008 at 8:00pm.

Nevertheless, the global culture has penetrated into most cultures as the hybridisation of cultural values has become the norm in many societies (Chan, 2010). However, consumers' demographics, the media, sociopolitical and institutional factors play a huge role in the pace at which acculturation takes place. Cultural gaps often persist in certain cultures in the event where consumers revert to indigenous cultural cues (Okoro, 2012). As such, efforts should be geared toward permeating the gap created by global and indigenous values. While there exists no standardised approach in permeating cultural gaps, Oyserman (2011) argued that the cultural context in which communication occurs serves as the most fundamental component of human interactions. In other words, there is a linear relationship between consumers' cultural context and the information consumers perceive as vital. The author distinguishes between two modalities of context-specific communication cultures: high-context and low-context communication cultures. Moreover, the IC cultural dimension has been linked to context-specific communication cultures. Sciffman and Wisenblit (2015) 
reported that people with individualistic cultural dispositions are easily persuaded by low-context communication cues while collectivistic cultures are more persuaded by high-context messages.

While people in individualistic societies have expressed likeness for personal goals and fulfilments, collectivistic societies are said to have preferences for in-group activities. From a South African perspective, the lessons fostered by Ubuntu values portray a deeper understanding of collectivism (Theron and Theron, 2010). While individualistic tendencies are common in Western countries, many Eastern countries, 'Arabspeaking' nations, African countries (excluding South Africa) and Asian countries tend towards collectivism. While cross-cultural consumer behaviour has not gained widespread popularity in South Africa, Hofstede's cross-national rankings show that South Africa ranked high on the individualism index (Hofstede and Hofstede, 2005); collectivistic dispositions have been identified in South Africa. Scholars opine that values fostered by Ubuntu have to a large extent contributed to the collectivistic outlook of the South African culture (Mufane, 2003). However, particular caution is advised in preventing the fallacy of predicting individual values based on country-level variables. Country-level variables are indicative of societal values which are not applicable to all ethnic groups in a country (Kalliny et al., 2011). Uskul and Oyserman (2010) confirmed that information is interesting and relevant when culturally framed and conveyed. Consumers have positive attitudes towards advertisements and are convinced by them when information processing is relatively simple. The cultural context of advertisements plays a pivotal role in the parameters consumers use to define 'fluent information'. de Mooij and Hofstede's (2011) findings offered a context-specific evaluation by affirming that individualists relate to advertising campaigns emphasising personal goals like; independence, achievement, fulfilment and individual rewards, whereas, advertising campaigns portraying in-group interactions and connectedness are more persuasive in collectivistic cultures. The structure of advertising campaigns could be an antecedent of the aforementioned scenario as Chaharsoughi and Yasory (2012) reported that marketing communication strategies could be used as a tool in the formation of values which could inform consumer behaviour.

As such, an inquiry into the African and Indian cross-cultural consumer behaviour is timeous in South Africa. While standardised country-level cultural attributes have not been established, collectivistic tendencies have been identified amongst African (Broodryk, 2008) and Indian consumers in South Africa (Vaheed et al., 2010). Although the indigenous factors responsible for this resemblance differ, the manifestations of the dominant cultural influences amongst these two racial groups are fundamentally similar. This notion is supported due to the commitment to relational and communal obligations (Burgess et al., 2002). While literature identified collectivistic tendencies amongst Africans and Indians, empirical evidence is paramount in validating this proposition from a marketing communication perspective. Nevertheless, the self-concept has been identified as one of the antecedents of culturally sensitive behaviour (Kopalle et al., 2010). Hawkins and Mothersbaugh (2010) reported that the self-concept is the lens through which consumers view themselves and thus, the picture consumers see when looking inward. Culture plays a pivotal role in how the 'self' is viewed. Two basic categories of the self-concept exist: the independent and interdependent self-concepts. While these categories are analogous to Hofstede's individualism versus collectivism cultural dimension, the independent selfconcept is shaped by personal achievements, desires and attributes, which makes individuals with an independent self-concept perceive themselves based on their accomplishments and social status (Shulruf et al., 2011).

On the contrary, Usunier and Lee (2013) argued that the interdependent self-concept is coined by communal and social involvements. Consumers who have interdependent self-concepts believe that fulfillment in life are rooted in the commitments to in-group activities. Individuals with an interdependent self-concept are defined by their obedience and connectedness to societal norms and values. The authors reiterated further by affirming that individuals with interdependent self-concepts view themselves as not being able to survive without others. Hence, interactions that enhance togetherness are favored. Most consumers fall in between the independent and interdependent continuum. These categories of self-concepts exert huge influence on consumer behaviour. Preferences for products, consumption patterns and marketing communication differ across variations in self-concepts. For instance, individuals with independent self-concepts relate more to advertisements emphasizing personal achievements while advertisements portraying in-group activities are more effective amongst individuals with interdependent self-concepts (Samovar et al., 2010), which makes the 
self-concept critical in determining the underlying attributes amongst consumers in individualists and collectivists societies. Some of these key differences are indicated in Table 1:

Table 1: Key differences between Individualist and Collectivist Societies

\begin{tabular}{|c|c|c|}
\hline Characteristics & Individualist & Collectivist \\
\hline Language & $\begin{array}{l}\text { Members of individualistic } \\
\text { spocieties } \\
\text { spontaneously use the word "I". }\end{array}$ & $\begin{array}{l}\text { Members of collectivistic } \\
\text { societies avoid the use of the } \\
\text { word "I". }\end{array}$ \\
\hline Personality & Individualists tend to be extroverts. & $\begin{array}{l}\text { Collectivists tend to } \\
\text { introverts. }\end{array}$ \\
\hline Emotions & $\begin{array}{l}\text { Happy moods are encouraged and sad } \\
\text { moods are discouraged. }\end{array}$ & $\begin{array}{l}\text { Happy moods are discouraged } \\
\text { and sad moods are encouraged. }\end{array}$ \\
\hline Consumption patterns & $\begin{array}{l}\text { Members' consumption patterns are not } \\
\text { influenced by the society. }\end{array}$ & $\begin{array}{l}\text { Members' consumption patterns } \\
\text { are influenced by the society. }\end{array}$ \\
\hline Sources of information & $\begin{array}{l}\text { Information is primarily sourced from } \\
\text { media. }\end{array}$ & $\begin{array}{l}\text { Information is sourced from } \\
\text { social interactions. }\end{array}$ \\
\hline Goals & $\begin{array}{l}\text { The ultimate goal of every individual is } \\
\text { self-actualization. }\end{array}$ & $\begin{array}{l}\text { Ultimate goals are harmony and } \\
\text { consensus. }\end{array}$ \\
\hline
\end{tabular}

Source: Adapted from Hofstede et al., (2010)

As indicated in Table 1, individualists are independent, priorities personal interest over in-group interests and tend to visualize people's behaviour based on personal experience. As a result, individualists are prone to be opinion leaders (Jandt, 2013). On the other hand, collectivists are interdependent, priorities in-group interests over personal interest and tend to generalize behaviour based on information derived from the group. By implication, collectivists are likely to take interests in and respond to advertising appeals emphasizing activities related to the family and the community (de Mooij, 2011). It is pertinent to emphasize that the focus should not only be directed at diversity, rather practitioners should take cognizance of cultural homogeneity. Taking an in-depth look at cultural values and in particular Hofstede's framework, research to date has identified a common ground and overlap along Hofstede's five cultural dimensions. Hence, efforts should be geared toward creating a balance in identifying societal cultural attributes. At the crux of this growing debate is the ability to carefully design strategies to identify possible diversity or homogeneity of cultural values, which could redress the challenges encountered in creating strategic competitive advantage (Ghemawat and Reiche, 2011).

\section{Methodology}

Cross-cultural marketing research has been predominantly studied from the emic approach; insider perspective and etic approach; outsider perspective (Usunier and Lee, 2013). The epistemological stance of this study is embedded within the emic approach. Since cultural influences are more predominant in distinct culturally clustered townships (Hofstede et al., 2010), the population units of this study comprised Africans and Indians residing in respective clustered townships in the city of Durban, South Africa. The research design for this study is both exploratory and descriptive in nature. Efforts were geared toward determining the appropriateness of the population units, during the preliminary exploratory phase of the study. A group of academics at the Durban University of Technology, South Africa, unanimously recommended the population units of this study. The fluidity of cultural values makes the use of standardized cultural measures vital in cross-cultural research (de Mooij, 2011). Since the focus of this research lies in investigating the elements of culturally constructed marketing communication values which have implications for attitudes towards marketing communication, a quantitative survey design was employed to accomplish the aim of the study. The sampling strategy for the study was largely influenced by the population representation of both races. The study draws on Gaski and Etzel's (1986) advertising scale of ICSM to measure attitudes toward marketing communication using the informative, annoying, dispensable, enjoyable and deceptive sub-constructs. The measures for culturally diverse marketing communication values were adapted from Hofstede and Hofstede's 
(2005) individualism and collectivism dimension using a 5 point Likert scale. The measures were designed to investigate the extent to which preferences for inner-directed motives and outer-directed motives moderate attitudes toward marketing communication. As such, it was important to determine the extent to which attitudes toward marketing communication were influenced by personal and in-group opinions of marketing communication.

Using a mall-intercept approach, a self-administrated questionnaire was distributed to the sample units at shopping malls located in the most popular African and Indian townships in Durban, viz. Umlazi and Chatsworth, respectively. The questionnaire for this study was translated into the native language of the African sample population viz. isiZulu, being the most prevalent medium of communication amongst the African sample. An isiZulu language practitioner was employed for the translation and two trained isiZulu speaking field assistants were also employed during the data collection. The most prevalent medium of communication amongst the Indian sample is English; hence the questionnaire for the Indian sample was administered in English language, although an Indian field assistant was employed during the data collection. The culturally embedded nature of the townships necessitated the need to ensure the data collection process was conducted in a culturally sensitive manner and complied with standardized ethical principles. A total number of 375 questionnaires were administered to respondents. While 283 completed questionnaires were received from Africans, all 92 questionnaires administered to Indians were fully completed, of which $81 \%$ and $19 \%$ were African and $19 \%$ Indian males, while $66 \%$ and $34 \%$ were African and Indian females, respectively. The majority of the African respondents fall within the age range of 18 and 24 years old, while $32 \%$ of the Indian respondents fall within the age range of 45 years and older. Data were analyzed using the Analysis of Variance (ANOVA) at a 95\% level of significance and Categorical Principal Component Analysis (CATPCA).

\section{Results and Discussion}

This study investigated respondents' attitudes toward marketing communication using the informative, annoying, dispensable, enjoyable and deceptive sub-constructs. The findings as shown in Figure 1 reveal that African respondents showed more inconsistent attitudes toward marketing communication than Indians. A further investigation reveals that African respondents perceive advertisements as more informative than their Indian counterparts, Indian respondents view advertisements as more annoying than their African counterparts. The cumulative result of attitudes toward marketing communication for both Africans and Indians shows that $49 \%$ of African respondents agree more with the measures on attitudes toward marketing communication than Indians (41\%).

\section{Figure 1: Attitudes toward Marketing Communication - Africans and Indians}

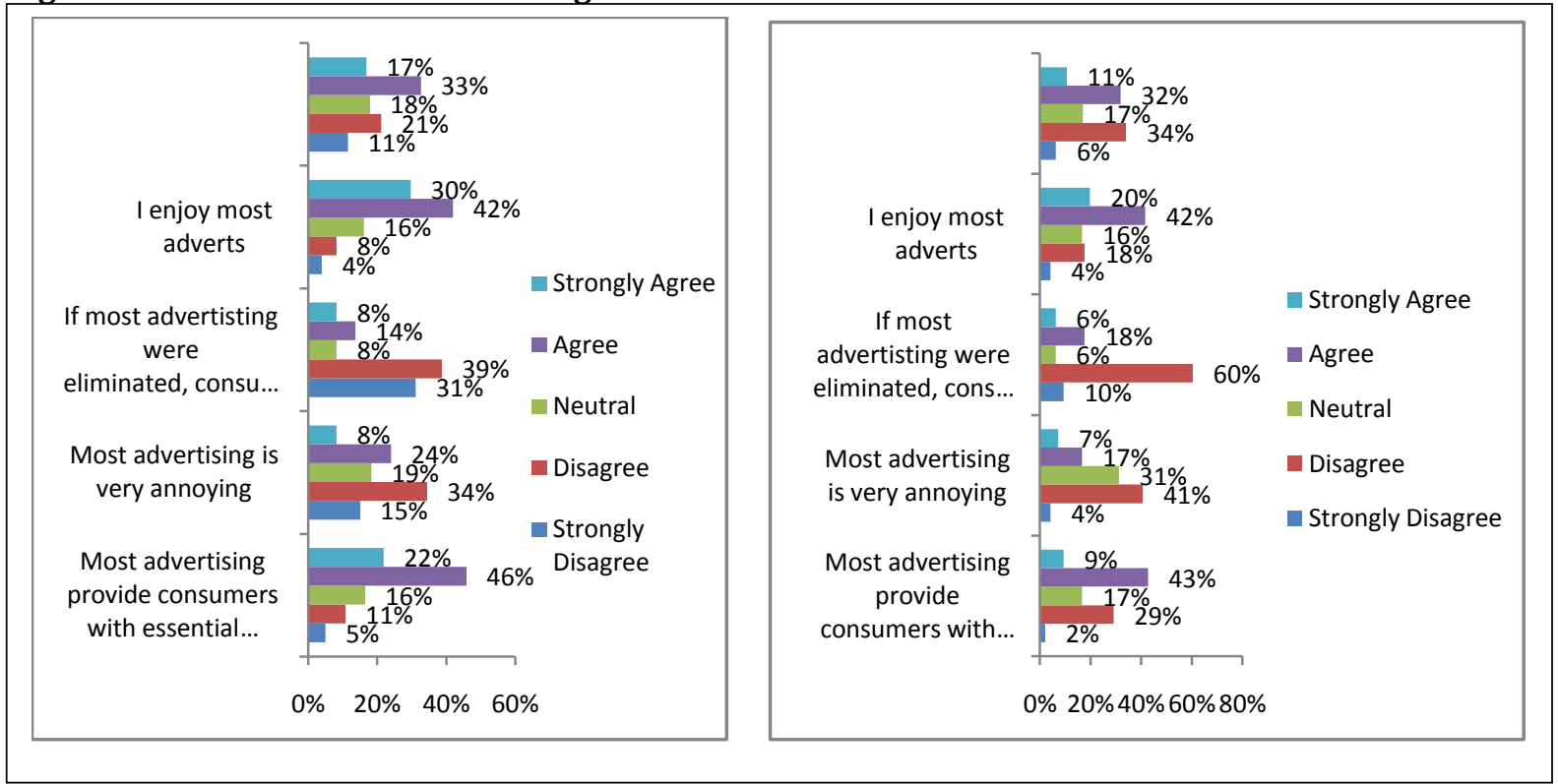


The dispensable measure reveals that African respondents consider advertisements as more dispensable than their Indian counterparts. However, African respondents perceive advertisements as more enjoyable and deceptive, compared to their Indian counterparts.

H1: Respondents' collectivistic tendencies will have significant influence on attitudes toward marketing communication.

The MCSCV measures are shown in Table 2. The first four measures viz. IND, were aimed at investigating respondents' individualistic tendencies toward marketing communication whilst the last four measures, viz. COL represent collectivistic measures. The mean scores obtained for the MCSCV measures reveal that both African and Indian respondents showed more individualistic than collectivistic tendencies toward marketing communication. However, both races scored low on item IND 3, which relates to respondents' preference for advertisements that portray personal needs rather than family needs. The result obtained further shows that both respondents deviated significantly from the mean as they scored high on item COL 3, which relates to the statement 'I often prefer advertisements that focus on how my family can benefit from the advertised product'.

Table 2: MCSCV Measures and Mean Values

\begin{tabular}{llll}
\hline IND/COL & Measures & $\begin{array}{l}\text { Mean } \\
\text { values for } \\
\text { Africans }\end{array}$ & $\begin{array}{l}\text { Mean } \\
\text { values for } \\
\text { Indians }\end{array}$ \\
\hline IND: $\mathbf{1}$ & $\begin{array}{l}\text { The opinions of my friends do not affect my buying } \\
\text { decisions, as long as I am convinced by the advertisements } \\
\text { of the products }\end{array}$ & 3.15412 & 3.89583 \\
IND: $\mathbf{2}$ & $\begin{array}{l}\text { I am more persuaded by advertisements that show } \\
\text { personal achievements } \\
\text { I prefer advertisements that stress my needs rather than } \\
\text { my family's needs }\end{array}$ & 2.10036 & 3.79167 \\
IND: $\mathbf{3}$ & $\begin{array}{l}\text { My choice of media has nothing to do with my family's } \\
\text { opinion }\end{array}$ & 3.39068 & 2.83333 \\
COL: $\mathbf{1}$ & $\begin{array}{l}\text { My beliefs about advertisements are very similar to those } \\
\text { of my parents }\end{array}$ & 2.62724 & 2.82292 \\
COL: $\mathbf{2}$ & $\begin{array}{l}\text { I would sacrifice not buying a preferred product if my } \\
\text { family did not like the advert }\end{array}$ & 2.54481 & 2.458342 \\
COL: $\mathbf{3}$ & $\begin{array}{l}\text { I often prefer advertisements that focus on how my family } \\
\text { can benefit from the advertised product }\end{array}$ & 3.91757 & 3.89583 \\
COL: $\mathbf{4}$ & $\begin{array}{l}\text { Everyone in my family likes the same advertisements } \\
\text { Note: Scale 1 } 1 \text { strongly disagree; } 5 \text { strongly agree }\end{array}$ & 2.34767 & 2.42709 \\
\hline
\end{tabular}

The ANOVA conducted to investigate the influence of MCSCV on respondents' attitudes toward marketing communication is shown in Table 3 below. Respondents' individualistic, collectivistic and overlapping tendencies toward marketing communication and their respective influence on attitudes toward marketing communication were tested for both races. The $\mathrm{p}$-values for the individualistic, collectivistic and overlapping tendencies are $0.00485(\mathrm{p}<0.05), 0.1427(\mathrm{p}>0.05)$, and $0.82847(\mathrm{p}>0.05)$, respectively, at 95\% level of significance. 
Table 3: Analysis of Variance for MCSCV and Attitudes toward Marketing Communication

\begin{tabular}{|c|c|c|c|c|c|c|c|c|}
\hline & $D f$ & SS & $M S$ & $\boldsymbol{F}$ & $\begin{array}{l}\text { Significance } \\
F\end{array}$ & & & \\
\hline Regression & 3 & 3.06236389 & 1.02079 & 3.783 & 0.0107278 & & & \\
\hline Residual & 371 & 100.119076 & 0.26986 & & & & & \\
\hline Total & 374 & 103.18144 & & & & & & \\
\hline & $\begin{array}{c}\text { Coefficient } \\
\mathrm{s} \\
\end{array}$ & $\begin{array}{c}\text { Standard } \\
\text { Error }\end{array}$ & t Stat & P-value & Lower 95\% & $\begin{array}{c}\text { Upper } \\
95 \% \\
\end{array}$ & $\begin{array}{l}\text { Lower } \\
95.0 \%\end{array}$ & $\begin{array}{l}\text { Upper } \\
95.0 \% \\
\end{array}$ \\
\hline Intercept & 2.5693387 & 0.19048029 & 13.48874 & $5.1 \mathrm{E}-34$ & 2.1947823 & 2.943895 & 2.1947824 & 2.9438951 \\
\hline Individualism & 0.1094338 & 0.03861922 & 2.833661 & 0.00485 & 0.0334938 & 0.185374 & 0.0334938 & 0.1853738 \\
\hline Collectivism & 0.0630449 & 0.04291912 & 1.46892 & 0.1427 & -0.0213503 & 0.147441 & -0.0213503 & 0.1474402 \\
\hline Overlapping & 0.0362139 & 0.16702114 & 0.216822 & 0.82847 & -0.292213 & 0.364641 & -0.2922126 & 0.3646407 \\
\hline
\end{tabular}

This finding shows that both races displayed more individualistic than collectivistic tendencies toward marketing communication. The finding also reveals that respondents' individualistic tendencies toward marketing communication has the most significant influence on attitudes toward marketing communication, which implies that respondents' with higher individualistic tendencies showed more favorable attitudes toward marketing communication. The result further confirms that there is a dissonance between the cultural disposition of consumers toward marketing communication and consumers' predetermined indigenous cultural dispositions. While this proposition is based on the sample of this study, such dissonance could also exist beyond this sample. Hence, the data does not support $H 1$. The five items which measured attitudes toward marketing communication were numbered $2.1-2.5$ while the items for the MCSCV were numbered 3.1 - 3.8 for COL and IND measures respectively. The CATPCA results as shown in Table 5 reveal that while Africans are more collectivistic than their Indian counterparts, both races scored low on the dispensability item, although Indians scored higher on the enjoyability item and low on the deceptive item.

Table 5: Variance Accounted for by Africans and Indians - Centroid Coordinates

\begin{tabular}{lrrrr}
\hline Items & $\begin{array}{r}\text { Africans } \\
\text { Dimension1 }\end{array}$ & Dimension 2 & $\begin{array}{c}\text { Indians } \\
\text { Dimension1 }\end{array}$ & Dimension 2 \\
\hline 2.1 & 0.148 & 0.413 & 0.254 & 0.033 \\
2.2 & 0.288 & 0.275 & 0.233 & 0.166 \\
2.3 & 0.378 & 0.052 & 0.661 & 0.057 \\
2.4 & 0.297 & 0.155 & 0.660 & 0.129 \\
2.5 & 0.164 & 0.391 & 0.642 & 0.018 \\
3.1 & 0.349 & 0.058 & 0.339 & 0.417 \\
3.2 & 0.436 & 0.069 & 0.222 & 0.067 \\
3.3 & 0.397 & 0.013 & 0.306 & 0.121 \\
3.4 & 0.290 & 0.172 & 0.259 & 0.462 \\
3.5 & 0.307 & 0.074 & 0.136 & 0.440 \\
3.6 & 0.360 & 0.026 & 0.179 & 0.371 \\
3.7 & 0.277 & 0.077 & 0.362 & 0.313 \\
3.8 & 0.326 & 0.024 & 0.375 & 0.135 \\
Active Total & 4.017 & 1.799 & 4.626 & 2.729 \\
\% of Variance & 30.899 & 13.837 & 35.584 & 20.99 \\
\hline
\end{tabular}

As shown in Figure 2, the Indian sample accounted for more variance compared to their African counterparts, although the collectivistic items accounted for more variance among the African sample, compared to the Indian sample. This finding further reiterates the saliency of the collectivistic disposition of Africans and the individualistic disposition of Indians, in relation to attitudes toward marketing communication, which does not support $H 1$. 
Figure 2: Component Loadings of Attitudes toward Marketing Communication and MCSCV for Africans and Indians
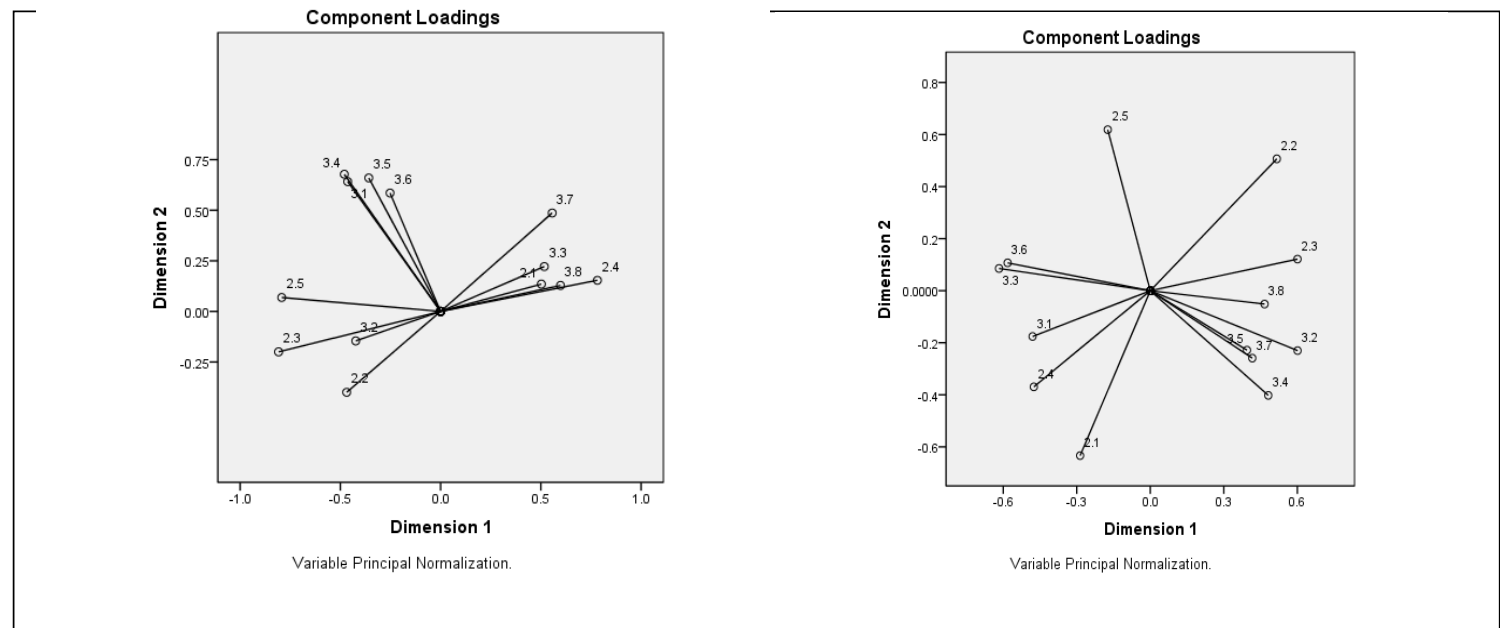

Variable Principal Normalization.

H2: Africans and Indians differ significantly based on the relationship between their demographic profile and attitudes toward marketing communication

The influence of respondents' demographic profile on attitudes toward marketing communication was tested at $95 \%$ level of significance. The breakdown of the p-values for the demographic profile of respondents is indicated in Table 4.

Table 4: Analysis of Variance for Demographic Statistics and Attitudes toward Marketing Communication

\begin{tabular}{|c|c|c|c|c|c|c|c|c|}
\hline \multicolumn{9}{|l|}{ ANOVA } \\
\hline & $D f$ & $S S$ & $M S$ & $F$ & Significance $F$ & & & \\
\hline Regression & 6 & 2,41782969 & 0,4029716 & 1,4716975 & 0,1867434 & & & \\
\hline Residual & 368 & 100,76361 & 0,2738142 & & & & & \\
\hline \multirow{2}{*}{ Total } & 374 & 103,18144 & & & & & & \\
\hline & $\begin{array}{c}\text { Coefficien } \\
\text { ts }\end{array}$ & $\begin{array}{c}\text { Standard } \\
\text { Error }\end{array}$ & t Stat & P-value & Lower 95\% & $\begin{array}{c}\text { Upper } \\
95 \%\end{array}$ & $\begin{array}{l}\text { Lower } \\
95.0 \%\end{array}$ & $\begin{array}{l}\text { Upper } \\
95.0 \%\end{array}$ \\
\hline Intercept & 3,361061 & 0,14562691 & 23,079942 & 1,609E-73 & 3,0746954 & 3,647426 & 3,0746954 & 3,647426 \\
\hline Gender & 0,020236 & 0,05676961 & 0,3564605 & 0,7217 & $-0,0913974$ & 0,131869 & $-0,091397$ & 0,13187 \\
\hline Race & $-0,172891$ & 0,07507089 & $-2,303042$ & 0,0218335 & $-0,3205132$ & $-0,025269$ & $-0,320513$ & $-0,02527$ \\
\hline Marital Status & $-0,006161$ & 0,05032889 & $-0,122425$ & 0,9026291 & $-0,1051298$ & 0,092807 & $-0,10513$ & 0,092807 \\
\hline Age Group & 0,027710 & 0,02321555 & 1,1936033 & 0,2334021 & $-0,0179416$ & 0,073369 & $-0,017942$ & 0,073362 \\
\hline $\begin{array}{l}\text { Education } \\
\text { level } \\
\text { Monthly }\end{array}$ & $-0,049979$ & 0,03861674 & $-1,294246$ & 0,1963922 & $-0,1259167$ & 0,025957 & $-0,125917$ & 0,025958 \\
\hline Income & $-0,016596$ & 0,04603546 & $-0,360514$ & 0,7186699 & $-0,107122$ & 0,073929 & $-0,107122$ & 0,073929 \\
\hline
\end{tabular}

Gender: p-value $=0.7217>0.05(5 \%)$, not significant. Race: -value $=0.0 .0218335<0.05(5 \%)$ significant. Marital Status: -value $=0.9026291>0.05(5 \%)$ not significant. Age Group: -value $=0.2334021>0.05(5 \%)$ not significant. Education level: $\mathrm{p}$-value $=0.1963922>0.05(5 \%)$ not significant. Monthly Income: $\mathrm{p}$-value $=$ $0.7186699>0.05(5 \%)$ not significant. This finding reveals that respondents' race is the only significant demographic factor influencing attitudes toward marketing communication, thus, all the other demographic factors tested in this study viz. age group, marital status, education level and monthly income have no significant influence on attitudes toward marketing communication.

This study has revealed that the interplay between consumers' indigenous cultural values and the cultural values held toward marketing communication have implications for consumers' attitudes toward marketing communication. This phenomenal interplay is not unfounded, considering the proliferation of the global 
culture, as observed by Uskul and Oyserman (2010), Chan (2010) and Schwaiger and Sarstedt (2011). Furrer, Liu and Sudharshan (2000) reported that consumers with higher individualistic tendencies have higher expectations of stimuli and tend to be independent and self-centered. Since such consumers place a high value on the self, it is not surprising that they will expect to be rewarded accordingly. However, consumers with higher collectivistic tendencies priorities in-groups activities that portray interdependence, fulfil communal obligations and loyalty to community members. In other words, activities that enhance harmony and peace with community members are prioritised in collectivistic societies (Shulruf et al., 2011). Hence, allegiance to the implicit institutional structures that govern behaviour in collectivistic cultures could play a huge role in the manifestation of multiple responses to stimuli.

Similarly, Oyserman (2011) maintained that although cultural values are shared, their manifestations are influenced by contexts. While respondents from both races showed 'favorable' and 'unfavorable' attitudes toward marketing, this finding is not unexpected as it corresponds with de Mooij's (2011) argument which elucidated that the exhibition of inconsistent attitudes toward stimuli is a common phenomenon in collectivistic cultures as opposed to consistent attitudes demonstrated by individualists. This implies that respondents' individualistic tendencies toward marketing communication (cultural specifics) cannot be equated to respondents 'cultural universals', as respondents' inconsistent attitudes toward marketing communication is an indication of their indigenous collectivistic dispositions. While prior research has generally reported a dissonance between consumers' indigenous dispositions and culturally contextualized dispositions, this study extends that knowledge based on the influence of the latter on attitudes toward marketing communication, from the African and Indian perspectives. The study highlights the predominant attributes of the two racial groups by drawing from the saliency of the individualism and collectivism cultural variations. The attitudes exhibited by both Africans and Indians suggest that efforts be geared toward developing strategies that override the unfavorable attitudes and harness the favorable attitudes exhibited by Africans and Indians.

This study has revealed that the idea of merely translating marketing communication messages into segment markets' local languages has proven to be unsustainable. Multicultural marketing extends beyond language translation, not only because this could lead to loss of meaning and zapping, but owing to the fact those consumers' marketing communication-specific cultural values also play a role in segment markets' attitudes toward marketing communication. Conversely, while consumers' subcultures and demographics serve as key segmentation variables, the overarching influence of racial identities on attitudes toward marketing communication cannot be overemphasized. The study provides guidelines for promoting cultural sensitivity in marketing communication strategies globally and serves as a pointer to prevailing challenges eminent in transforming local brands into global brands vis-à-vis an attitudinal approach.

\section{Conclusion and Recommendations}

In sum, the ability of marketing practitioners to develop culturally sensitive marketing communication strategies is dependent of the flexibility of campaigns to prevailing cultural cues in target markets. As such, marketing practitioners should acknowledge the changing needs of consumers by adapting strategies accordingly. The cultural sensitivity of marketing communication strategies is beneficial to both consumers and marketing practitioners, in terms of its ability to redress prevailing cultural misunderstanding. The adaptability and sensitivity of marketing communication strategies is therefore critical for generating new sources of strategic competitive advantage, given that consumers' attitudes toward marketing communication could be a reflection of their underlying cultural disposition and cultural values held toward marketing communication.

It is apparent that the alignment of marketing communication strategies to prevailing consumers' cultural dispositions remains one of the key sources of strategic competitive advantage. Fundamental to the operationalisation of the aforementioned will be an investigation into prevailing cultural cues in target markets, especially marketing strategies designed for target markets residing in clustered geographical locations with a shared history of transitory cultural diversity. The dynamic nature of socially constructed cues, particularly with the combination of social media cues demand that marketing practitioners adapt transcending cultural values accordingly. The application of this understanding to marketing strategies can 
serve as a platform for enhancing mass customization. Due to limited advertising budgets, it is recommended that marketing strategies incorporate consumers' overlapping individualistic and collectivistic tendencies by combining cues which transcend between both cultural dimensions, in order to offset potential culturally sensitive attitudes. The demonstration of the need for self-actualization in marketing strategies, while embracing communitarianism, could trigger reverse psychological effects in attitudes toward marketing communication.

It will be equally important to identify the influence of potential dissonance between cultural values. As such, future research could shift the focus of this study to other dimensions such as power distance, masculinityfemininity, uncertainty avoidance and long-short term orientation. It will be equally important to examine these dimensions cross-culturally, in order to generate new insights about the intensity of the underlying cultural forces influencing consumer behaviour across cultures and societies, especially in uniquely multicultural societies. Also, experimental investigations of cultural influences on the actual behaviour of consumers in the real shopping experience could also open new lines of research in cross-cultural marketing research. Such research could enhance our understanding of cross-cultural marketing communication and the sensitivity of global marketing communication strategies.

Acknowledgement: The authors of this paper acknowledge the support of the Durban University of Technology, South Africa for the findings of this paper, which form part of the results of a larger academic study conducted under the auspices of the university.

List of Abbreviations: MCSCV - Marketing Communication-Specific Cultural Values

\section{References}

Baek, T. H. \& Morimoto, M. (2012). Stay away from me: examining the determinants of consumer avoidance of personalized advertising. Journal of advertising, 40(1), 59-76.

Bearden, W. O., Netemeyer, R. G. \& Haws, K. L. (2011). Handbook of marketing scales: multi-item measures for marketing and consumer behavior research. (3rd ed.), California: SAGE.

Bhaktawar, N. \& Burger, D. (2010). Pocket guide to South Africa ( $8^{\text {th }}$ ed.), Pretoria: GCIS.

Blythe, J. (2008). Consumer behaviour, London: Thomson learning.

Brittany, R. L. D. \& Ronald, J. F. (2011). Missing the mark: advertising avoidance and distractor devaluation. Journal of advertising, $40(2), 51-62$.

Broodryk, J. (2008). Ubuntu African life coping skills: theory and practice. Recreating linkages between theory and praxis in educational leadership, 26 - 27 October. http://www.topkinisis.com

Bulmer, S. \& Buchanan-Oliver, M. (2010). Experiences of brands and national identities. Australian marketing journal, 18,199-205.

Burgess, S., Harris, M. \& Mattes, R. (2002). SA Tribes: who we are, how we live and what we want from life in the new South Africa. Claremont: David Philip publishers.

Chaharsoughi, S. A. \& Yasory, T. H. (2012). Effect of sales promotion on consumer behaviour based on culture. African journal of business management, 6(1), 98-102.

Chan, A. M. (2010). The importance of understanding levels issues in cross-cultural marketing research. International review of business research papers, 6(1), 18-29.

deMooij, M. (2011). Consumer behaviour and culture: Consequences for global marketing and advertising (2 $2^{\text {nd }}$ ed.), California: SAGE.

deMooij, M. \& Hofstede, G. (2011). Cross cultural consumer behaviour: A review of research findings. Journal of international consumer behaviour, 23, 181-192.

Du Plessis, P. J. \& Rousseau, G. G. (2007). Buyer behaviour (3 ${ }^{\text {rd }}$ ed.), New York: Oxford University Press.

Furrer, O., Shaw-Ching Liu, B. \& Sudharshan, D. (2000). The relationships between culture and service quality perceptions: Basis for cross-cultural market segmentation and resource allocation. Journal of service research, 2(4), 355-371.

Gaski, J. F. \& Etzel, M. J. (1986). The index of consumer sentiment toward marketing. The journal of marketing, 7, 1-8.

Ghemawat, P. \& Reiche, S. (2011). National cultural differences and multinational business. Globalization note series, 1-15. 
Hawkins, D., I. and Mothersbaugh D., L. (2010). Consumer behavior: Building marketing strategy (11 th ed.), New York: McGraw-Hill.

Hofstede, G. \& Hofstede, G. J. (2005). Cultures and organizations: Software of the mind (2nded.), New York: McGraw-Hill.

Hofstede, G., Hofstede, G. J. \& Minkov, M. (2010). Cultures and organizations: Software of the mind (3rd ed.), New York: McGraw-Hill.

Jandt F. E. (2013). An introduction to intercultural communication: Identities in a global community ( $7^{\text {th }}$ ed.), California: SAGE.

Kalliny, M., Saran, A., Ghanem, S. \& Fisher, C. (2011). Cultural differences and similarities in television commercials in the Arab world and the United States. Journal of global marketing, 24(1), 41-57

Kopalle, P. K., Lehmann, D. R. \& Farley, J. U. (2010). Consumer expectations and culture: The effect of belief in Karma in India. Journal of consumer research, 37(2), 251-263.

Morimoto, M. (2012). The influence of acculturation and in-group bias on source credibility: The case of Asian American female consumers. Journal of promotion management, 18(2), 254-274.

Morling, B. \& Lamoreaux, M. (2008). Measuring culture outside the head: A meta- analysis of individualismcollectivism in cultural products. Personality and social psychology review, 12(3)199-221.

Mufane, P. (2003). African culture and managerial behaviour: Clarifying the connections. South African journal of business management, 34(3), 17-28.

Ndhlovu, T. P. (2011). Corporate social responsibility and corporate social investment in South Africa: The South African Case. Journal of African business, 12, 72-92.

Okoro, E. (2012). Cross-cultural etiquette and communication in global business: Toward a strategic framework for managing corporate expansion. International journal of business and management, 7(16), 130-138.

Oyedele, A. \& Minor, M. S. (2012). Consumer culture plots in television advertising from Nigeria and South Africa. Journal of advertising, 41(1), 91-107.

Oyserman, D. (2011). Culture as situated cognition: cultural mindsets, cultural fluency and meaning making. European review of social psychology, 22, 164-214.

Prendergast, G., Cheung, W. \& West, D. (2010). Antecedents to advertising avoidance in China. Journal of current issues and research in advertising, 32(2), 87-100.

Quester, P. G., Pettigrew, S. \& Hawkins, D. (2011). Consumer behaviour: Implications for marketing strategy (6 ${ }^{\text {th }}$ ed.), North Ryde: McGraw-Hill.

Samovar, L. A., Porter, R. E. \& McDaniel, E. R. (2010). Communication between cultures (7th ed.), Boston: Wadsworth.

Schiffman, L. G. \& Wisenblit, J. (2015). Consumer behaviour. (11th ed.), Essex: Pearson.

Schwaiger, M. \& Sarstedt, M. (2011). Corporate branding in a turbulent environment. Journal of brand management, 19, 179-181.

Sen, S., Du, S. \& Bhattacharya, C. (2016). Corporate social responsibility: A consumer psychology perspective. Current Opinion in Psychology, 10, 70-75.

Shulruf, B., Hattie, J. \& Dixon, R. (2011). Intertwinement of individualist and collectivist attributes and response sets. Journal of social, evolutionary and cultural psychology, 5(1), 51-65.

Statistics South Africa. (2015). Mid-year population estimates. www.statssa.gov.za.

Soontiens, W. \& De Jager, J. W. (2008). South African values: A reflection on its 'Western' base. African journal of business management, 2(12), 222-229.

Solomon, M. R. (2013). Consumer behavior: buying, having, and being (10 th ed.), Essex: Pearson.

Theron, L. C. \& Theron, A. M. C. (2010). A critical review of studies of South African youth resilience, 19902008. South African journal of science, 106(7/8), 1-8.

Usunier, J. C. \& Lee, J. A. (2013). Marketing across cultures (6 ${ }^{\text {th }}$ ed.), Harlow: Pearson.

Uskul, A. K. \& Oyserman, D. (2010). When messages fit salient cultural-frame, messages fell more persuasive. Journal of psychology and health, 25(3), 321-337.

Vaheed G., Deshai, A. \& Waetjen T. (2010). Many lives: 150 years of being Indian in South Africa. Pietermaritzburg: Heather Hannaway. 